\title{
THE 16 APRIL 2015 MW6.1 EARTHQUAKE SEQUENCE NEAR KASOS ISLAND AT THE EASTERN HELLENIC SUBDUCTION ZONE
}

\author{
Kiratzi A.A. \\ Aristotle University of Thessaloniki, Department of Geophysics, 54124, Thessaloniki, Greece, kira \\ tzi@geo.auth.gr
}

\begin{abstract}
Broad band seismic waveforms are used to determine the source model of the 16 April 2015 (UTC 18:07:44) earthquake, Mw6.1, which occurred 14 km SW of Kasos Island, in the eastern Hellenic subduction zone. The mainshock is connected with oblique leftlateral motion on a reverse fault, dipping to SE. Most of the aftershocks are compatible with strike-slip or oblique normal faulting, with the T-axes showing along arc extension. A finite fault slip inversion was performed, allowing for the rake angle to vary across the fault, to capture the variation in the slip vectors. The rupture initiated in the lower crust, at a centroid depth of $23 \mathrm{~km}$, and propagated mainly towards SW. The slip is confined in depth within $\sim 17 \mathrm{~km}$ and $27 \mathrm{~km}$, mainly in a single asperity, with the peak slip of the order of $60 \mathrm{~cm}$. The slip model provided synthetic seismograms which matched satisfactory the observed, and with forward modelling the ShakeMap was calculated. The 2015 Kasos earthquake sequence is compatible with shear motions parallel to the strike of the subduction zone. It provides evidence that part of the deformation in the eastern Hellenic subduction is taken up by the simultaneous operation of reverse faulting and of minor strike-slip and oblique normal faulting, with slip vectors aligned $\sim$ parallel to the Pliny and Strabo Trenches and the long axis of the local bathymetry.
\end{abstract}

Keywords: earthquake, slip model, focal mechanism, Hellenic trench.

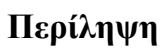

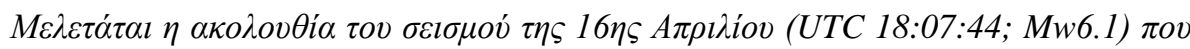

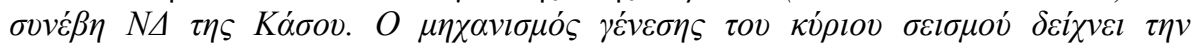

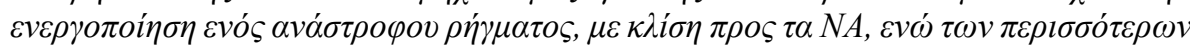

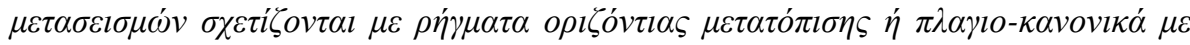

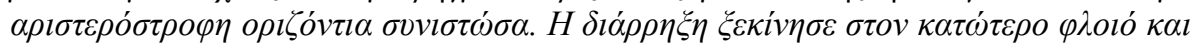

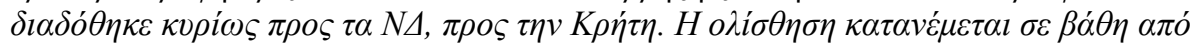

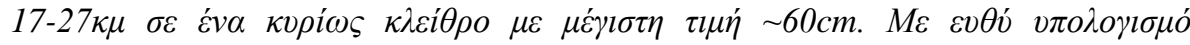

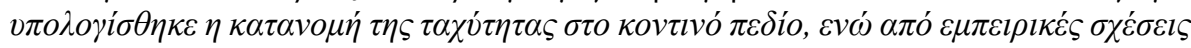

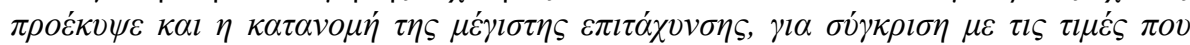
$\kappa \alpha \tau \alpha \gamma \rho \alpha \dot{\varphi \eta \kappa \alpha v ~ \sigma \tau o v \varsigma ~ \varepsilon \pi \imath \tau \alpha \chi v v \sigma l o \gamma \rho \alpha ́ \varphi o v \varsigma . ~ O ~ \sigma \varepsilon l \sigma \mu o ́ \varsigma ~ \tau \eta \varsigma ~ K \alpha ́ \sigma o v ~ \kappa \alpha \tau \alpha \delta \varepsilon l \kappa v v ́ \varepsilon l ~ o ́ \tau l ~}$

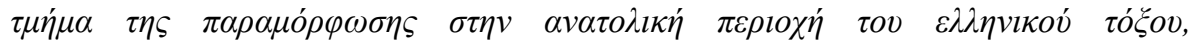

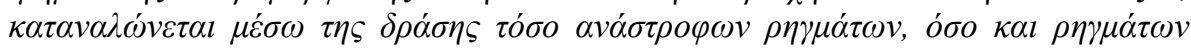

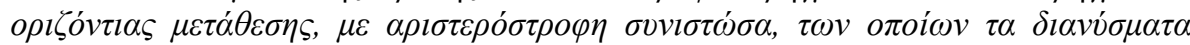

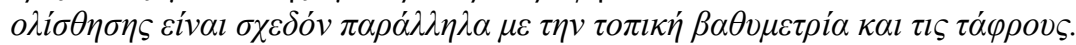

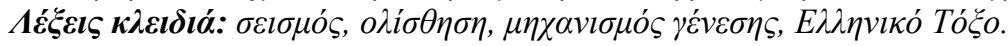




\section{Introduction}

The Eastern Mediterranean active tectonics are mainly controlled by the convergence between Nubia (Africa) and Eurasia at less than 10mm/yr and the rapid movement of southern Aegean southwards, away from Eurasia, at $\sim 30 \mathrm{~mm} / \mathrm{yr}$. In this framework, the front part of the Nubia lithosphere, the Mediterranean seafloor, subducts rapidly $(\sim 40 \mathrm{~mm} / \mathrm{yr})$ beneath the Aegean, forming the well-known Hellenic Subduction Zone. The subduction zone is overlain by a thick $(\sim 10 \mathrm{~km})$ pile of sediments which form an accretionary prism, known as the Mediterranean Ridge (see Kiratzi, 2014 and references therein). The bathymetry from Peloponnese, to south of Crete and up to Rodos, is dominated by a number of trenches, the Hellenic Trench dominating in the west, between Peloponnese and western Crete (Fig. 1).

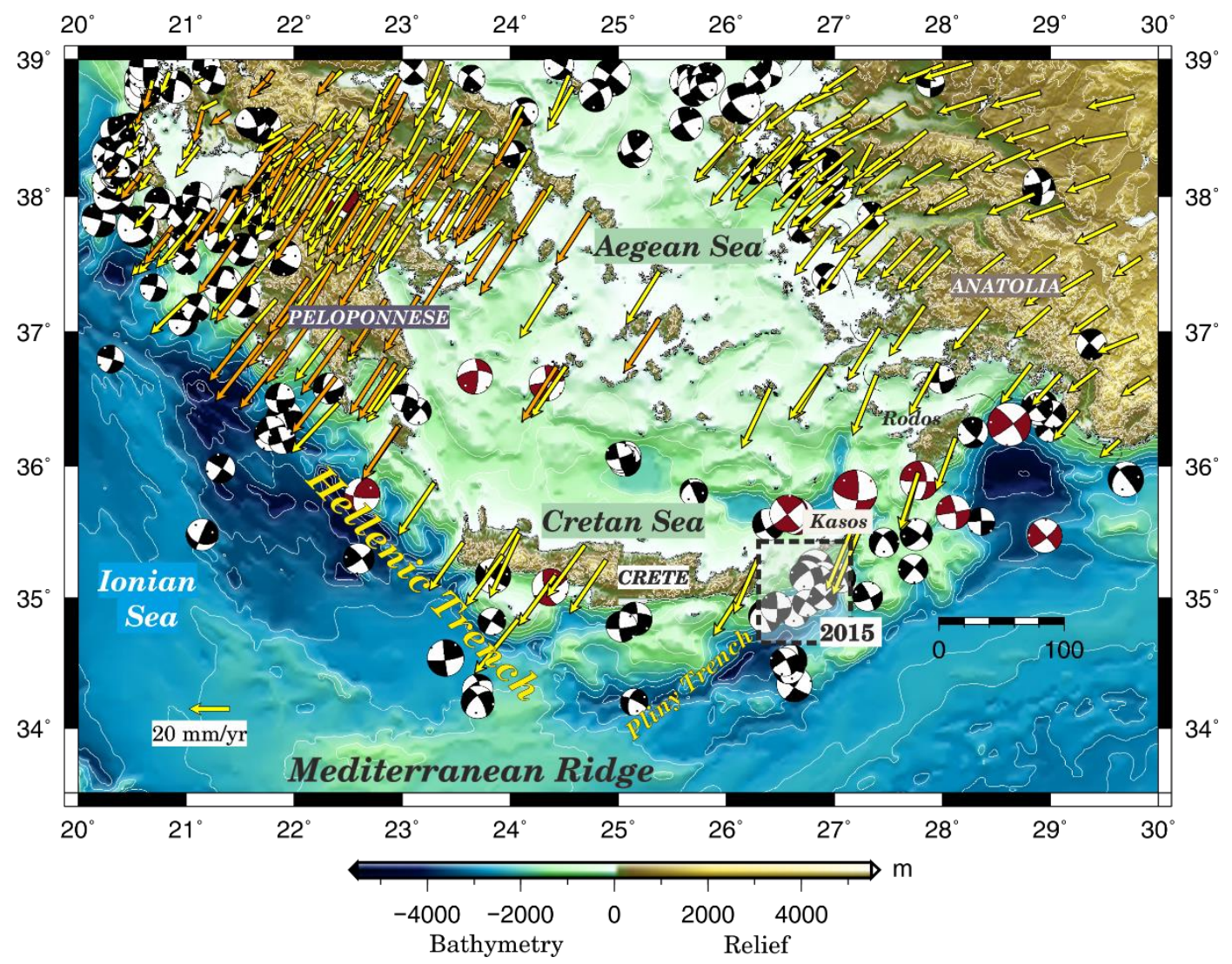

Figure 1 - The 2015 Kasos sequence (within the dashed rectangle) and the tectonic setting of the eastern Hellenic subduction zone. Only strike-slip focal mechanisms are plotted for earthquakes with $M>6.0$. Black beach-balls denote shallow depths and red beach balls denote focal mechanisms for intermediate depth $(\mathrm{h}>=40 \mathrm{~km})$ earthquakes. The arrows indicate GPS velocity vectors relative to Eurasia (GPS data from Chousianitis et al., 2015).

The Hellenic Trench does not mark the actual interface of contact between the down going Nubia lithosphere and the overriding Aegean lithosphere. This interface is marked by the occurrence of earthquakes compatible with low angle thrust mechanisms, dipping towards the overriding Aegean plate. Evidently, these shallow-dipping planes project beneath the pile of sediments, south of Crete. Taking into account the large thickness of these sediments it is very doubtful whether the interface reaches the surface, and more probably it is hidden beneath the sediments, in the form of a blind thrust (Shaw, 2012). The overriding Aegean plate mainly encompasses along-arc E-W extension. This type of normal faulting is widespread in southern Aegean, that is south of the volcanic arc, and 
is also evident within the mainland of Crete Island. The subducting Nubia lithosphere undergoes along arc compression, as revealed by the distribution of the focal mechanisms of intermediate depth ( $\mathrm{h}>40 \mathrm{~km}$ ) earthquakes (Taymaz et al., 1991). Apart from the low-angle thrust and reverse focal mechanisms, which are the signature of the Africa-Eurasia convergence, along the subduction zone strike-slip focal mechanisms are also observed, which are not clearly connected with the interface or the subducting slab. Here, we mainly focus on the reverse and strike-slip faulting on the eastern section of the subduction zone, where the 16 April 2015 (Mw6.0-6.1) earthquake sequence occurred, near Kasos Island. We study the focal mechanism of the mainshock and of its strongest aftershocks, and calculate a finite-fault slip model for the mainshock, in an attempt to better understand the deformation pattern along the eastern subduction zone. The instrumentally recorded seismicity along the subduction zone is rather moderate in size, and the kinematics along this part of the subduction zone are still poorly understood.

\section{Characteristics of the 2015 Kasos sequence}

\subsection{Teleseismic body waveform modelling of the mainshock}

The MT5 code (McCaffrey et al., 1991; Zwick et al., 1994) was used to jointly invert the P and SH waveforms, and solve for the strike, dip, rake, centroid depth, seismic moment and source time function, using Green's functions calculated for a point source. For this purpose, broad band GDSN seismograms were downloaded from the Incorporated Research Institutions for Seismology (IRIS) Data Management Centre. The selected stations are in the $30^{\circ}-80^{\circ}$ distance range to avoid complications relating to core phases and shallow velocity structures. The velocity model used was for one layer of $30 \mathrm{~km}$ thickness $\left(\mathrm{Vp}=6.5 \mathrm{~km} / \mathrm{s}\right.$; Vs=3.7 km/s; $\left.\rho=2.8 \mathrm{gr} / \mathrm{cm}^{3}\right)$ over a half-space $\left(\mathrm{Vp}=8.0 \mathrm{~km} / \mathrm{s} ; \mathrm{Vs}=4.5 \mathrm{~km} / \mathrm{s} ; \rho=3.3 \mathrm{gr} / \mathrm{cm}^{3}\right)$. A water layer of $1.5 \mathrm{~km}$ layer thickness was applied on top of the velocity structure. Prior to the inversion the waveforms were corrected for the instrument response and band pass filtered between 0.01 and $1 \mathrm{~Hz}$. The corrected velocity waveforms were integrated to displacement, and they were re-convolved with the response of the WWSSN 15-100s long period instrument. Finally, the waveforms were decimated at $1 \mathrm{~s}$ and were cut 20 s before and 80 s after the phase arrival. $28 \mathrm{P}$-waves and $17 \mathrm{SH}$ waveforms were finally inverted. The azimuthal coverage is not perfect, and parts of the focal sphere quadrants are not well sampled. This is a common feature with the southern Aegean Sea earthquakes and the geometry of the global stations. The seismograms were weighted according to azimuthal density, and the weights of the SH waveforms were further downscaled to compensate for their generally larger amplitudes. The source time function was parameterized as a series of overlapping isosceles triangles, each having a half duration of 1s. The routine minimizes the weighted squared residuals between observed waveforms and synthetic seismograms computed by combining direct arrivals ( $\mathrm{P}$ or $\mathrm{S}$ ) with near-source reflections ( $\mathrm{pP}$ and $\mathrm{sP}$, or $\mathrm{sS}$ ). The calculated synthetic waveform amplitudes were corrected for geometrical spreading (Langston and Helmberger, 1975) and for anelastic attenuation using a Futterman $\mathrm{Q}$ operator with $\mathrm{t}^{*}=1.0 \mathrm{~s}$ for $\mathrm{P}$ and $\mathrm{t}^{*}=4.0 \mathrm{~s}$ for $\mathrm{SH}$ waves - any uncertainties in $\mathrm{t}^{*}$ have little effect on other source parameters, but mainly result in uncertainties in source duration and seismic moment.

The best fitting solution is summarized in Table 1 and Figure 2. The mechanism shows predominantly reverse motion with a significant component of strike-slip motion, with the centroid depth at $23 \mathrm{~km}$, when the Moho depth in this region is $\sim 26 \mathrm{~km}$. The source duration of this model is $\sim 7 \mathrm{~s}$. The solution provides an acceptable fit (R/D 75\%) between observed and synthetic waveforms in most stations. The uncertainty in the strike of the nodal planes is large $\left(-15^{\circ},+0^{\circ}\right)$, whereas for the dip and rake are of the order of $\pm 7^{\circ}$, and for the depth is $-4,+2 \mathrm{~km}$. From the published solutions for the mainshock (Table 1) our solution is closer to the one determined by NOA-GI. Even though all solutions mostly agree on the centroid depth, there is a large variation, among them, regarding the strike of the nodal planes, which in our modelling as well, the uncertainties regarding the strike, are significant. 
16 April 2015 Kasos earthquake strike 75; dip 40; rake 56; h $23 \mathrm{~km} / \mathrm{Mw6} .1$

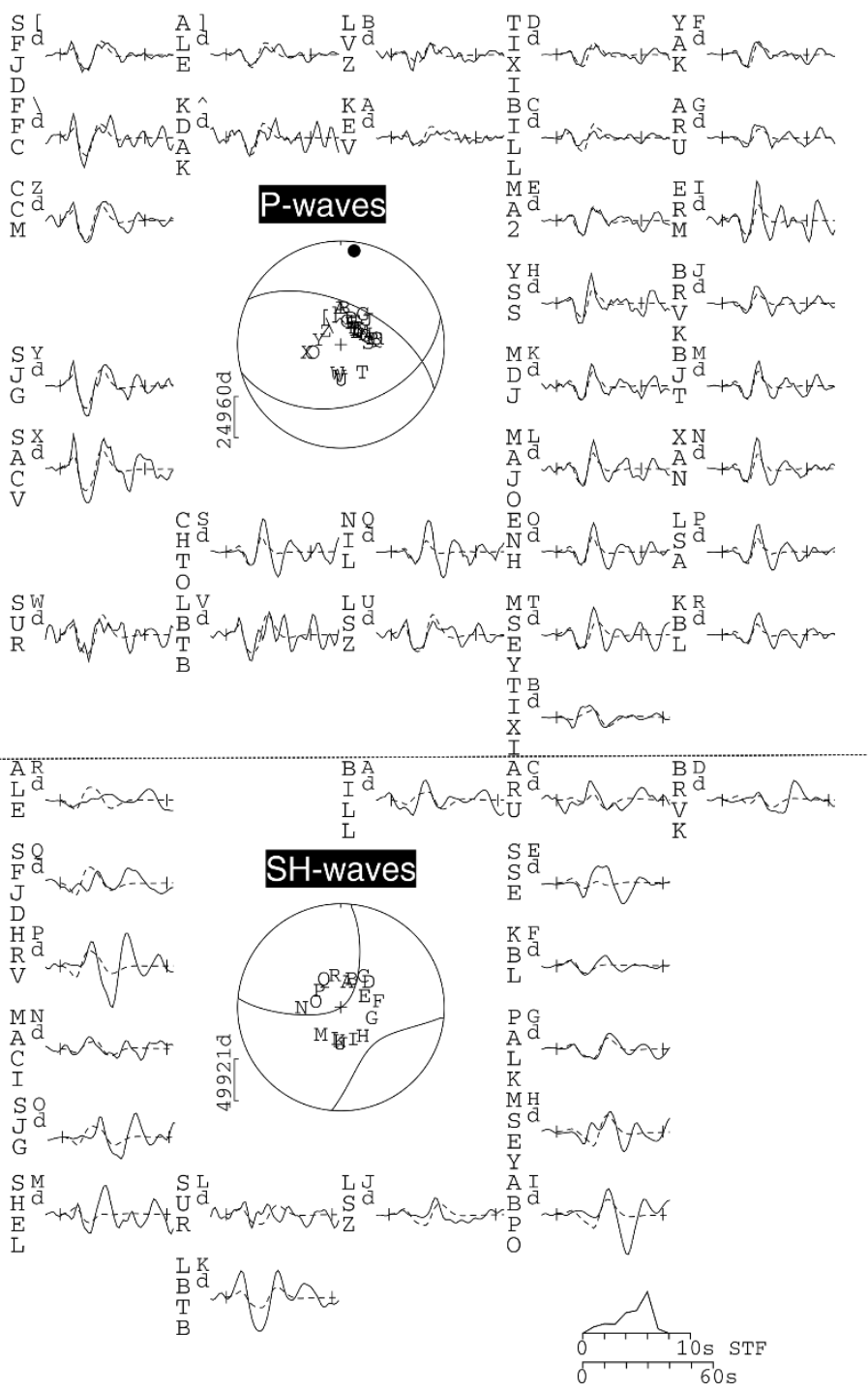

Figure 2 - Mechanism of the 2015 Kasos mainshock from the inversion of $P$ and SH body waves. The top focal sphere shows the lower hemisphere projection of the $\mathbf{P}$ waveform nodal planes and the positions of the seismic stations used. The lower focal sphere shows the SH nodal planes. Capital letters next to the stations names correspond to the position on the focal sphere. The inversion window is marked with vertical lines in each waveform. Dashed lines represent synthetics and straight lines, observed waveforms. The source time function scale and the waveforms scale are shown at the right corner. The amplitude scale for the waveforms is shown left to each focal sphere.

\subsection{Distribution of aftershocks and their focal mechanisms}

To calculate the focal mechanisms of the aftershocks the moment tensor inversion technique of Dreger (2002), as described in Roumelioti et al. (2011) was applied. The seismic data were broad band velocity waveforms retrieved from the Hellenic Unified Seismic Network (HUSN) and the 
Turkish Seismological Network, operated by the Kandilli Observatory. Prior to the inversions, the waveforms were corrected for the instrument response, integrated to displacement, rotated to transverse and radial components, band-pass filtered, and resampled at $1 \mathrm{sps}$. The cut-off frequencies of the filter applied were 0.02 and $0.08 \mathrm{~Hz}$ for the mainshock and the strongest aftershocks, while moderate size aftershocks were filtered between 0.05 to $0.08 \mathrm{~Hz}$. Synthetic Green's functions were computed using the frequency-wavenumber integration code developed by Saikia (1994). Both the waveforms and the synthetics were filtered using the same bandwidth selected. Two 1-D velocity models were tested (e.g., Karagianni et al., 2005 and Novotny et al., 2001) in their ability to describe the low frequency content of the recorded broad band waveforms, and in most cases the latter provided better fits.

Figure 3 (top left) shows the location of the mainshock and of the 20150417 UTC 02:05 Mw5.4 strongest aftershock (asterisks), together with the best located aftershocks. The majority of the aftershocks are forming a $\sim \mathrm{N}-\mathrm{S}$ trending cloud between Kasos and western Crete. A number of minor structures east of Karpathos were also activated. Figure 3 (top right) shows the focal mechanisms of the mainshock and of the strongest aftershocks (Table 1), and the cross-section (bottom of the figure) perpendicular to the strike of local bathymetry, clearly shows that the strongest events occurred mainly in the lower crust, and extend in depth from 20 to $\sim 40 \mathrm{~km}$. It is the shallow seismicity that obscures the pattern of the aftershocks, forming the N-S cloud that does not coincide by any of the nodal planes, and shows the activation of smaller-scale shallower structures.

Table 1 - Source parameters of the mainshock and the strongest aftershocks of the 16 April 2015 Kasos Island sequence.

\begin{tabular}{|c|c|c|c|c|c|c|c|c|c|c|c|c|c|c|}
\hline \multirow{2}{*}{$\begin{array}{c}\text { Date } \\
\text { Y/M/D }\end{array}$} & \multirow{2}{*}{$\begin{array}{c}\begin{array}{c}\text { Origin } \\
\text { Time }\end{array} \\
\text { h:m:s }\end{array}$} & \multirow{2}{*}{$\begin{array}{l}\text { Lat } \\
{ }^{\circ} \mathbf{N}\end{array}$} & \multirow{2}{*}{$\begin{array}{c}\text { Long } \\
{ }^{\circ} \mathbf{E}\end{array}$} & \multirow{2}{*}{$\begin{array}{c}\mathrm{h} \\
\mathrm{km}\end{array}$} & \multirow[t]{2}{*}{ Mw } & \multicolumn{3}{|c|}{$\begin{array}{l}\text { NODAL } \\
\text { PLANE } 1\end{array}$} & \multicolumn{3}{|c|}{$\begin{array}{c}\text { NODAL } \\
\text { PLANE } 2\end{array}$} & \multicolumn{2}{|c|}{ Slip Vector } & \multirow[t]{2}{*}{ R } \\
\hline & & & & & & $\mathbf{s}^{0}$ & $d^{\circ}$ & $\mathbf{r}^{\circ}$ & $\mathbf{s}^{\circ}$ & $d^{\circ}$ & $\mathbf{r}^{\circ}$ & $\mathbf{a z}^{\circ}$ & $\mathrm{pl}^{\circ}$ & \\
\hline 20150416 & 18:07:44 & 35.23 & 26.82 & 23 & 6.1 & 75 & 40 & 56 & 296 & 58 & 115 & 26 & -32 & 1 \\
\hline 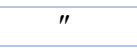 & $"$ & 35.03 & 26.85 & 24 & 6.1 & 56 & 43 & 21 & 310 & 76 & 131 & 40 & -14 & 2 \\
\hline$"$ & $"$ & 35.23 & 26.82 & 28 & 6.0 & 71 & 51 & 68 & 284 & 44 & 115 & 14 & -46 & 3 \\
\hline 20150416 & 18:52:37 & 35.17 & 26.90 & 22 & 4.7 & 233 & 83 & -6 & 324 & 84 & -173 & 234 & 6 & 1 \\
\hline 20150416 & $: 02: 14$ & 35.13 & 26.85 & 26 & 5.0 & 236 & 86 & 5 & 146 & 8 & 176 & 236 & -5 & 1 \\
\hline$"$ & 19:02:18 & 35.17 & 26.80 & 20 & 5.0 & 249 & 71 & 38 & 145 & 55 & 156 & 235 & -36 & 2 \\
\hline 20150416 & 20:01:13 & 35.19 & 26.75 & 25 & 4.1 & 324 & 83 & -176 & 234 & 86 & -7 & 144 & 4 & 3 \\
\hline 150416 & $21: 52: 24$ & 35.22 & 26.86 & 21 & 4.0 & 218 & 68 & 1 & 128 & 8 & 158 & 218 & -1 & 3 \\
\hline 20150417 & 01:50:45 & 35.17 & 26.74 & 25 & 4.1 & 223 & 65 & -26 & 325 & 67 & -152 & 235 & 23 & 3 \\
\hline 20150417 & 02:05:42 & 35.16 & 26.74 & 25 & 5.4 & 234 & 71 & -35 & 337 & 57 & -157 & 247 & 33 & 1 \\
\hline$"$ & 02:05:44 & 35.00 & 26.61 & 25 & 5.5 & 231 & 77 & -40 & 332 & 51 & -163 & 242 & 39 & 2 \\
\hline 20150417 & $10: 23: 46$ & 35.20 & 26.67 & 28 & 4.2 & 239 & 71 & 2 & 148 & 88 & 161 & 238 & -2 & 3 \\
\hline 20150417 & $16: 39: 41$ & 34.96 & 26.74 & 24 & 4.5 & 215 & 81 & -9 & 306 & 81 & -171 & 216 & 9 & 1 \\
\hline 20150422 & $20: 19: 58$ & 35.29 & 26.71 & 28 & 4.2 & 222 & 70 & 10 & 129 & 81 & 160 & 219 & -9 & 3 \\
\hline 20150427 & 14:16:32 & 35.17 & 26.82 & 28 & 4.0 & 227 & 26 & 39 & 101 & 74 & 111 & 191 & -16 & 3 \\
\hline 20150511 & 05:02:01 & 35.01 & 26.90 & 32 & 4.5 & 46 & 82 & 2 & 316 & 88 & 172 & 46 & -2 & 3 \\
\hline 20150609 & $21: 49: 48$ & 35.07 & 26.80 & 24 & 5.4 & 236 & 80 & 19 & 143 & 71 & 169 & 233 & -19 & 1 \\
\hline
\end{tabular}

Ref (R): 1: this study; 2: GCMT solution; 3: NOA-GI (National Observatory of Athens- Geodynamic Institute). 

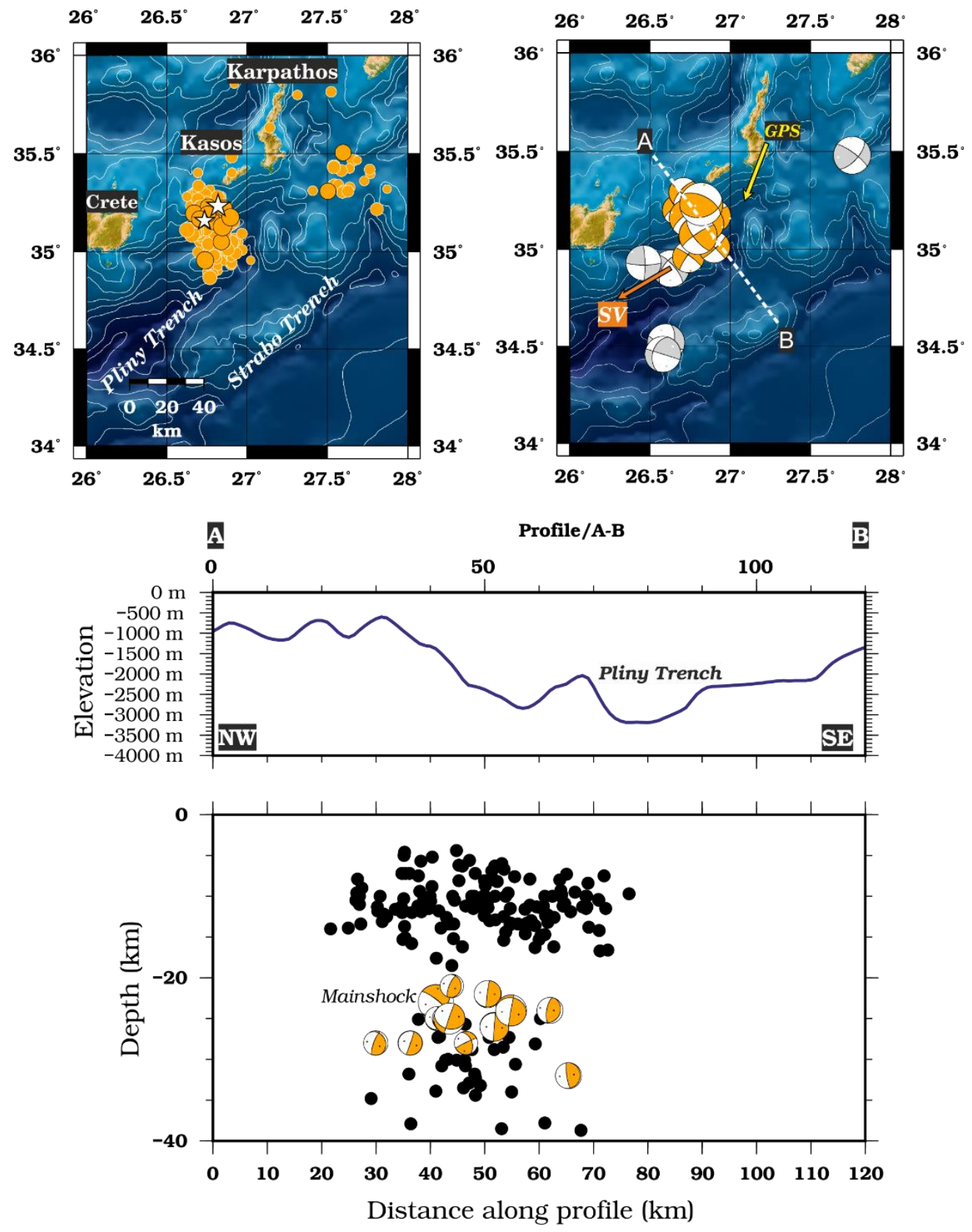

Figure 3 - top left: Epicentres of the sequence (orange circles) and the location of the mainshock and the strongest aftershock (stars); top right: focal mechanism of the mainshock and of the aftershocks (orange beach balls) together with those from previous strong events (grey beach balls). Oblique normal and strike-slip motions are prevailing in most of the cases whose slip vector is marked with the orange arrow $(S V)$, compatible with left-lateral shear parallel to the trench. The GPS velocity vector shows the motion of the islands relative to Eurasia, which is oblique to the trench; bottom: cross-section along A-B line shows that a) the main sequence is confined at the northern edge of the Pliny Trench and the strongest aftershocks alongside the mainshock occurred below $20 \mathrm{~km}$, in the lower crust, and b) it is the shallower seismicity that obscures the pattern of the ENE-WSW trending fault plane. 
From the cross section (Fig. 3) it can be deduced that the mainshock is compatible with reverse faulting that dips to the SE. This is confirmed by the subsequent analysis for the calculation of the slip model, during which the nodal plane which provides statistically significant better fit to the data, can be identified. The ENE trending plane that dips towards SE implies a moderate component of left-lateral strike-slip motion. It must be noted, that the strongest Mw5.4-5.5 aftershock, implies oblique normal faulting and E-W extension, like the one observed within the overriding Aegean plate. The focal depths of all events analysed are around $20-32 \mathrm{~km}$. The average orientation of the slip vectors, for the earthquakes listed in Table 1 , is $220^{\circ}$. This orientation is oblique to the local orientation of the GPS velocity vectors $\left(\sim 195^{\circ}\right)$, but is parallel to the strike of the subduction zone and aligns with the long axis of the basin bathymetry (Pliny and Strabo Trenches).

\section{Slip Model of the Mainshock}

\subsection{Method}

The slip distribution onto the fault plane is investigated through a linearized least-squares inversion with simultaneous smoothing (e.g., Hartzell and Heaton, 1983; Dreger and Kaverina, 2000; Kaverina et al., 2002) as applied to previous Aegean earthquakes (Kiratzi et al., 2013 and references therein). Extensive resolution and checkerboard tests of the applied method are included in Benetatos et al. (2007). The source has finite dimensions and the fault plane is discretized into a number of subfaults. The rupture is assumed to propagate from the hypocentre with constant rupture speed and each subfault is allowed to rupture only once as the rupture front passes. In our model parameterization, the slip history of each subfault was represented by an appropriate number of isosceles triangles, and moreover, the rake angle was allowed to vary over the fault plane. Synthetic waveforms are finally derived as the result of the summation of the individual subfault contributions, using appropriate time delays for both the time needed for the wave to propagate from the hypocentre to the recording stations and the time needed for the rupture front to propagate from the hypocentre to the centre of each subfault. The applied linearized least-squares inversion is combined with slip positivity, spatial gradient smoothing and moment minimization constraints. The slip positivity constraint implies that slip is allowed to occur only along the rake direction, while the moment minimization constraint reduces spurious slip in the later portions of the rupture.

\subsection{Finite-fault slip model}

Initial inversion runs indicated that the SE dipping plane provided significant better Variance Reduction (63\%) compared to the conjugate nodal plane (44\%). Thus the slip model was calculated for the geometry of this plane (Table 1). To capture the variation of slip vectors onto the fault plane, the rake angle was allowed to vary $\pm 45^{\circ}$. The fault plane was discretized into $35 \times 35$ square subfaults, of $1 \times 1 \mathrm{~km}^{2}$ area, along strike and dip, respectively. The subfaults were sized so that the rupture process is smooth and the transit time across them, taking into account the rupture velocity, is also smooth. The dimensions of the fault model were chosen large enough to allow the slip to find its preferred position. The rise time and the rupture velocity, were grid searched for the optimal values, and were finally adopted equal to $0.5 \mathrm{~s}$ and $2.7 \mathrm{~km} / \mathrm{s}$, respectively. We separately calculated the dipslip and strike-slip components, finally using the vector summation for both components.

Figure 4 summarizes the preferred slip model, in fault coordinates centred at the rupture initiation point at $12 \mathrm{~km}$ depth, for the parameterization adopted. Slip is confined within 17 to $27 \mathrm{~km}$ depth, mainly in a single asperity. Minor slip is also found in a smaller asperity at southwest, alongside rather unstable spurious shallow slip. The average slip is $9 \mathrm{~cm}$ and the peak slip is $\sim 60 \mathrm{~cm}$ in accordance with the predictions of empirical scaling relations. The total moment of the model is $1.55 \mathrm{e} 18 \mathrm{~N}-\mathrm{m}$, corresponding to Mw6.1, in accordance with the reported values to the European Mediterranean Seismological Centre (EMSC) from the various seismological agencies. The slip model predicts synthetic waveforms that fit the observed ones very satisfactorily as can be seen from the comparison (Fig. 5). 

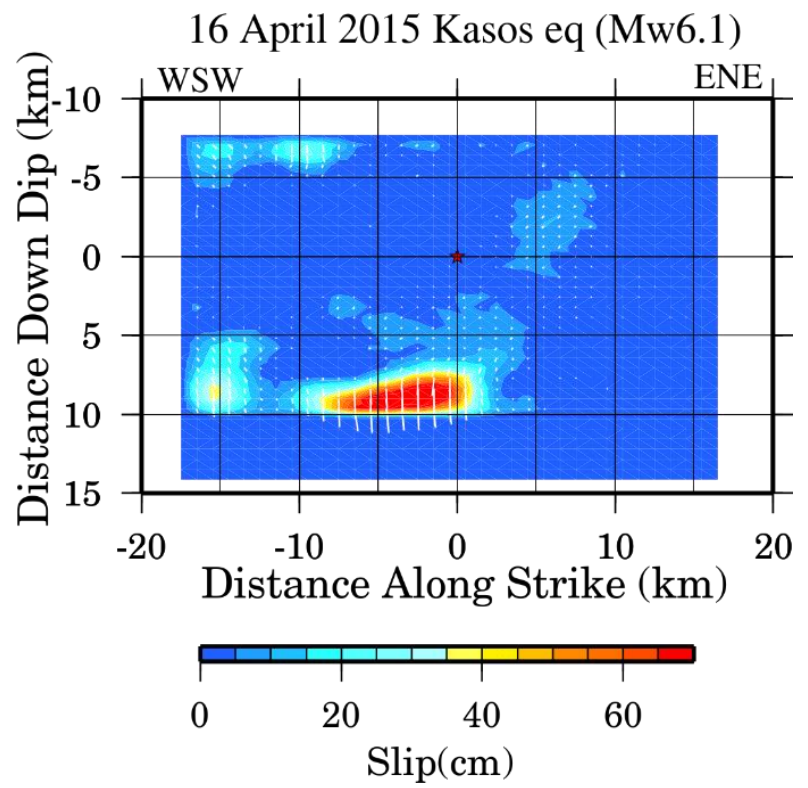

Figure 4 - Slip model for the mainshock, obtained from finite fault inversion, using regional broad band seismic waveforms. The white lines denote the variable rake onto the fault plane, and the red asterisk marks the rupture initiation point (note that it is at $12 \mathbf{~ k m}$ ). The locus of maximum slip $(\sim 60 \mathrm{~cm})$ is confined within 17 and $27 \mathrm{~km}$ in agreement with the centroid depth from the teleseismic modelling.
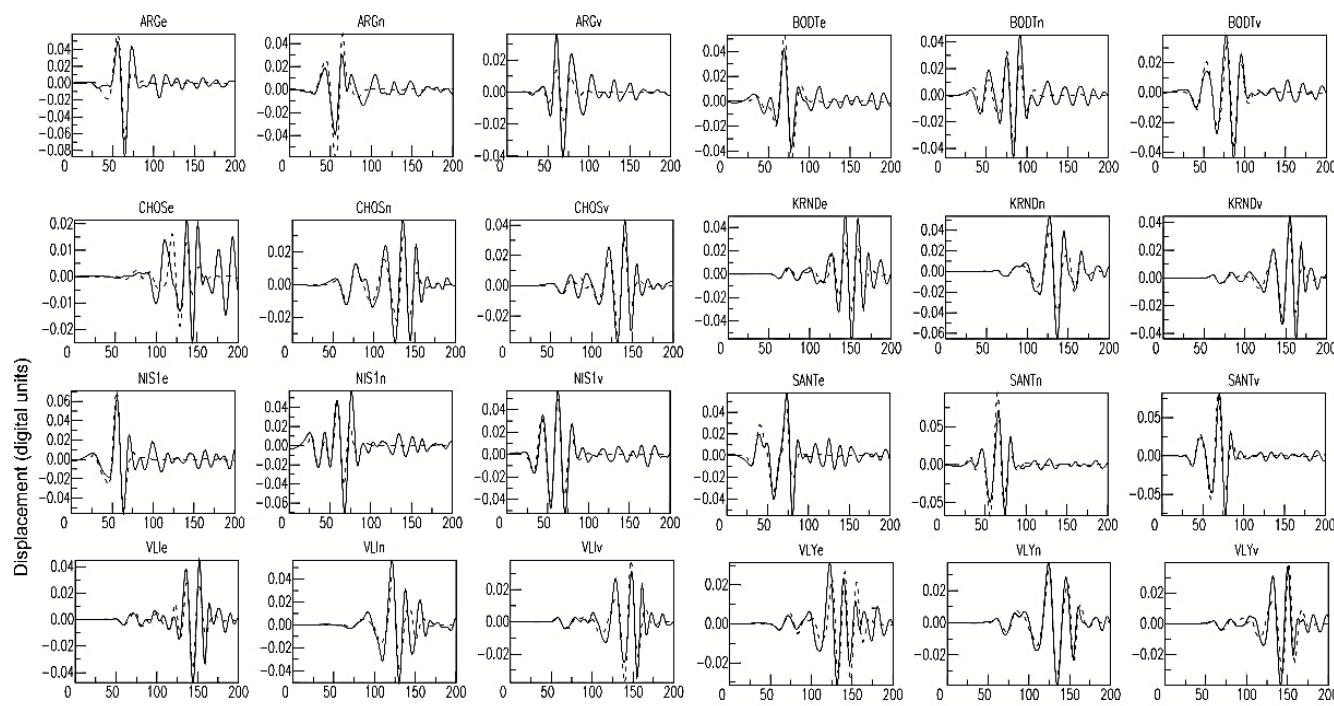

Time (s)

Figure 5 - Comparison of synthetic waveforms (dashed lines) calculated using the slip model for the mainshock, with the observed ones (straight lines) for all station components included in the slip model inversion.

\subsection{ShakeMap from forward modelling}

The slip model was used in a forward modelling procedure in order to calculate synthetic velocity records in a grid of nodes covering the broader region. These velocity records were then used to map the spatial variation of ground motions. The mainshock was recorded in a number of accelerographs, located in 
Kasos, Crete and Karpathos islands (Table 2). The acceleration on the instrument located in a rock site in Zakros (Crete) at a distance of $56 \mathrm{~km}$ was $56.0 \mathrm{~cm} / \mathrm{s}^{2}$. The recording at an alluvium site at the Town Hall on Karpathos island, at a distance of $47 \mathrm{~km}$, was $98.5 \mathrm{~cm} / \mathrm{s}^{2}$ (Kalogeras and Melis, 2015).

Table 2 - Recorded PGA's at selected accelerographs located on nearby locations.

\begin{tabular}{|c|c|c|c|c|c|c|c|c|}
\hline \multirow{2}{*}{$\begin{array}{l}\text { Station } \\
\text { Code }\end{array}$} & \multirow{2}{*}{ Location } & \multirow{2}{*}{$\begin{array}{l}\text { Surface } \\
\text { geology }\end{array}$} & \multicolumn{2}{|c|}{$\begin{array}{c}\text { Station } \\
\text { coordinates }\end{array}$} & \multirow{2}{*}{$\begin{array}{c}\text { Distance } \\
\text { km }\end{array}$} & \multicolumn{3}{|c|}{ PGA $\left(\mathrm{cm} / \mathrm{s}^{2}\right)$} \\
\hline & & & Lat ${ }^{\circ} N$ & Lon $^{\circ} \mathbf{E}$ & & $\mathrm{Z}$ & $X(E)$ & $\mathrm{Y}(\mathrm{N})$ \\
\hline KSS1 & Kasos Isl. & $\mathrm{n} / \mathrm{a}$ & 35.4189 & 26.9209 & 23 & 32.1 & 29.3 & 43.2 \\
\hline KRPA & Karpathos & Alluvium & 35.5082 & 27.2092 & 47 & 25.6 & 83.3 & 98.5 \\
\hline ZKR & Zakros & limestone & 35.1146 & 26.2171 & 56 & 20.0 & 49.8 & 56.0 \\
\hline SIT2 & Sitia & $\mathrm{n} / \mathrm{a}$ & 35.2059 & 26.1070 & 68 & 33.0 & 78.4 & 60.3 \\
\hline
\end{tabular}

The map of Figure $6 \mathrm{~b}$ compares the distribution of PGA as this is predicted from the empirical scaling relations of Skarlatoudis et al. $(2003,2007)$. The predicted accelerations on the Kasos island are of the order of 60 to $70 \mathrm{~cm} / \mathrm{s}^{2}$, and overestimate by $\sim 40 \%$ the values actually recorded by the KSS1 strong motion instrument. On the other hand, the empirical GMPs seem to accurately predict the values on the limestone site on the ZKR station in Crete. It must be noted here, that all maps presented in Figure 6, have been corrected for the site effect, using the topography gradient, as proxy, for the values of Vs30, following Wald and Allen (2007).

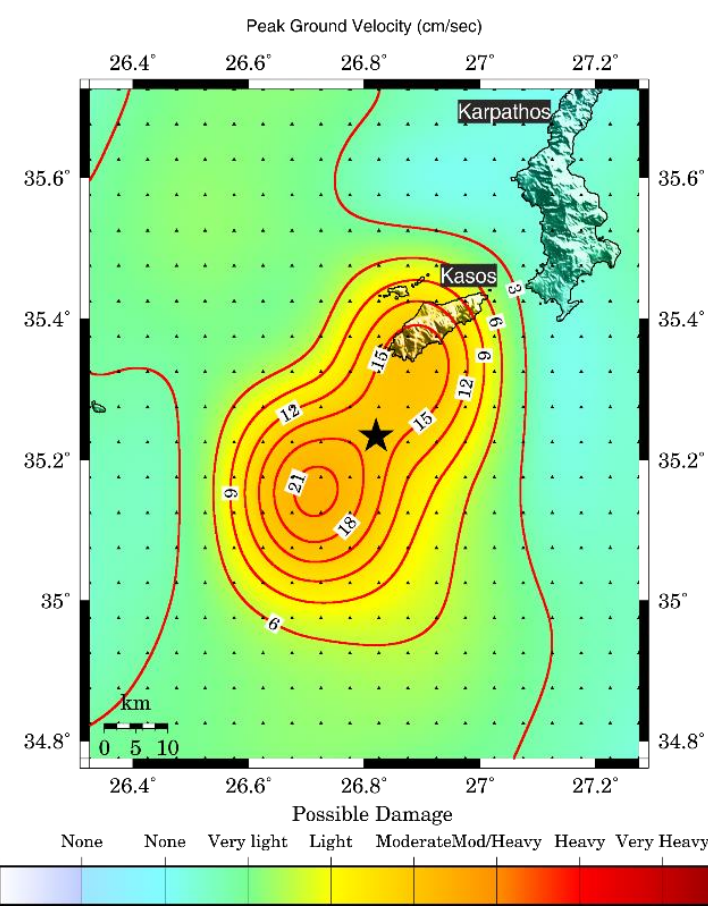

a)

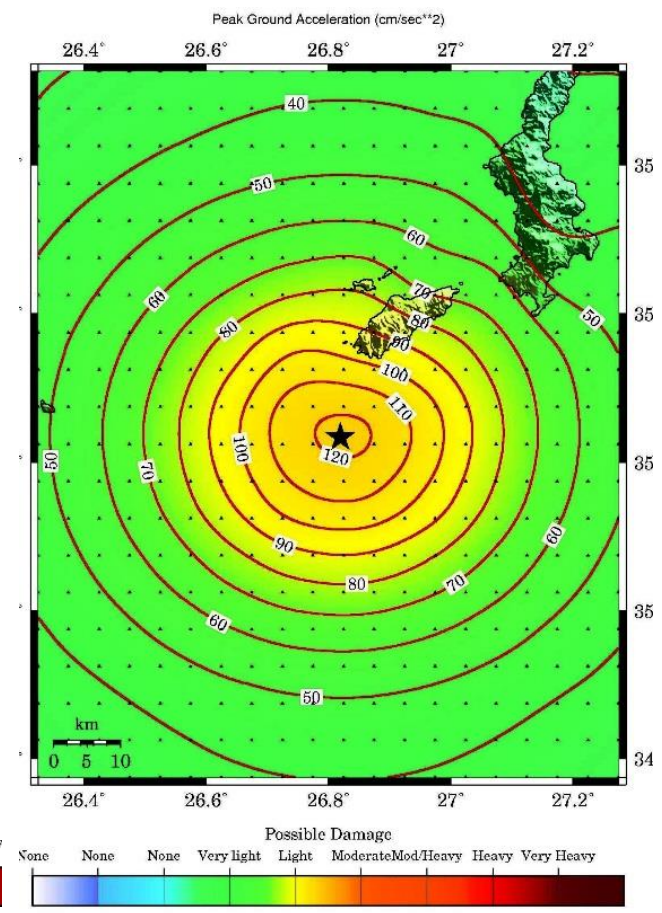

b)

Figure 6 - a) ShakeMap (PGVs in $\mathrm{cm} / \mathrm{s}$ ) of the 2015 mainshock, produced using forward modelling and the slip model (Fig. 4). b) Distribution of PGA in $\mathbf{c m} / \mathrm{s}^{2}$ using the empirical relations of Skarlatoudis et al. (2003, 2007). 


\section{Summary}

The Kasos 2015 earthquake which occurred in the eastern Hellenic subduction zone is connected with rupture of a reverse fault, at $23 \mathrm{~km}$ depth, trending $\sim$ ENE-WSW and dipping to the SE. The calculated slip model, using broad band regional waveforms, and finite-fault inversion techniques, shows that the slip was mainly confined in two patches onto the fault plane. This slip model predicts synthetic waveforms that satisfactorily match the observed ones. The ShakeMap calculated from the slip model shows moderate ground shaking, mainly along the southern coast of the island of Kasos, and offshore towards southwest.

The Kasos sequence occurred shoreward of the Pliny Trench at depths that range from 20 to $\sim 40 \mathrm{~km}$. The Moho at this region is at $\sim 26 \mathrm{~km}$ and the thickness of the seismogenic layer is approximately 40 $\mathrm{km}$. The focal mechanism of the mainshock (reverse faulting) implies that the P-axis is trending $\mathrm{N} 164^{\circ} \mathrm{E}$. It must be noted that the focal mechanisms of most of the strong aftershocks are compatible with left lateral strike-slip and oblique normal faulting, mainly along ENE-WSW $\left(\sim 50^{\circ}\right)$ trending planes, which implies along arc extension. Within this framework, the GPS obtained velocity vectors (Fig. 1) show that the motion of the Karpathos, Kasos and western Crete relative to Africa is oblique to the strike of the subduction zone, as well as the long axis of the Pliny and Strabo Trenches. This oblique convergence motion implies that a trench-parallel and a trench - perpendicular component is expected. The trench - parallel component is mainly accommodated by the distributed strike-slip and oblique normal faulting earthquakes, as is the case of most aftershocks in these sequence, whose slip vectors are oriented parallel to the trench and imply left-lateral shear at this part of the subduction zone. The trench - perpendicular component is expected to be accommodated by large reverse faults, parallel to the strike of both the subduction zone and to the Pliny and Strabo Trenches. In fact, these trenches in analogy with the Hellenic Trench, may equally well be the surface expressions of large scale reverse faults, which are geometrically required to accommodate part of the deformation. The 2015 Kasos sequence is compatible with trench-parallel shear motions.

\section{Data and resources}

Digital seismic waveforms were retrieved from the Hellenic Broad Band Seismic Network (NOA: doi:10.7914/SN/HL; AUTH: doi:10.7914/SN/HT; UPSL: doi:10.7914/SN/HP). The catalogues AUTH and NOA were used. Moment tensors were computed using the code developed by Douglas Dreger and Sean Ford of the Berkeley Seismological Laboratory, and Green's functions were computed using the FKRPROG software developed by Chandan Saikia. All figures were produced using the GMT software (Wessel and Smith, 1998). The Earthquake Planning and Protection Organization (EPPO-OASP) is gratefully thanked for partial support of the operation of the AUTh Seismological Network. Nikos Theodoulidis provided the accelerograms from stations KSS1 and SIT2.

\section{Acknowledgments}

This research has been co-financed by the European Union (European Social Fund - ESF) and Greek national funds through the Operational Program "Education and Lifelong Learning" (Project THALES- MIS 377335 - Characterization of site conditions in Greece for realistic seismic ground motion simulations: pilot application in urban areas).

\section{References}

Benetatos, C., Dreger, D. and Kiratzi, A., 2007. Complex and segmented rupture associated with the 14 August 2003 (Mw 6.2) Lefkada (Ionian Islands) earthquake, Bulletin of the Seismological Society of America, 97(1B), 35-51, doi: 10.1785/ 0120060123.

Chousianitis, K., Ganas, A. and Evangelidis, C., 2015. Strain and rotation rate patterns of mainland Greece from continuous GPS data and comparison between seismic and geodetic moment release, J. Geophys. Res. Solid Earth, 120, doi: 10.1002/2014JB011762. 
Dreger, D., 2002. Manual of the Time-Domain Moment Tensor Inverse Code (TDMT_INVC), Release 1.1, Berkeley Seismological Laboratory, 18 pp.

Dreger, D. and Kaverina, A., 2000. Seismic remote sensing for the earthquake source process and near - source strong shaking: a case study of the October 16, 1999 Hector Mine earthquake, Geophys. Res. Lett., 27, 1941-1944.

Hartzell, S.H. and Heaton, T., 1983. Inversion of strong ground motion and teleseismic waveform data for the fault rupture history of the 1979 Imperial Valley, California, earthquake, Bull. Seism. Soc. Am., 73, 1553-1583.

Kalogeras, I. and Melis, N., 2015. Preliminary report: The April 16, 2015 Kasos earthquake, SE Aegean, Greece, 1-10, available at: http://accelnet.gein.noa.gr/strong-earthquake-reports.

Karagianni, E.E., Papazachos, C.B., Panagiotopoulos, D.G., Suhadolc, P., Vuan, A. and Panza, G.F., 2005. Shear velocity structure in the Aegean area obtained by inversion of Rayleigh waves, Geophys. J. Int., 120, 127-143.

Kaverina, A., Dreger, D.S. and Price, E., 2002. The combined inversion of seismic and geodetic data for the source process of the 16 October, 1999 Mw7.1 Hector Mine, California, earthquake, Bull. Seism. Soc. Am., 92, Special issue on the Hector Mine earthquake, 1266-1280.

Kiratzi, A., 2014. Mechanisms of Earthquakes in Aegean, Encyclopedia of Earthquake Engineering, Article ID: 382074, ISBN: 978-3-642-36197-5.

Kiratzi, A., Aktar, M. and Svigkas, N., 2013. The 10 June 2012 Mw6.0 earthquake sequence in the easternmost end of the Hellenic Arc, Bulletin of the Geological Society of Greece, XLVII, ID: 230.

Langston, C.A. and Helmberger, D.V., 1975. A procedure for modelling shallow dislocation sources, Geophys. J. R. Astr. Soc., 42, 117-130.

Novotny, O., Zahradník, J. and Tselentis, G., 2001. North-western Turkey earthquakes and the crustal structure inferred from surface waves observed in Western Greece, Bull. Seism. Soc. Am., 91, 875-879.

McCaffrey, R., Abers, G. and Zwick, P., 1991. Inversion of Teleseismic Body Waves, International Association of Seismology and Physics of the Earth's Interior, $166 \mathrm{pp}$.

Roumelioti, Z., Kiratzi, A. and Benetatos, C., 2011. Time Domain Moment Tensors of Earthquakes in the broader Aegean Sea for the years 2006-2007: the database of the Aristotle University of Thessaloniki, J. Geodynamics, doi: 10.1016/j.jog.2010.01.011.pdf.

Saikia, C.K., 1994. Modified frequency - wavenumber algorithm for regional seismograms using Filon's quadrature: modelling of Lg waves in Eastern North America, Geophys. J. Int., 118, 142-158.

Shaw, B., 2012. Active Tectonics of the Hellenic Subduction Zone, Springer Theses, 1, doi: 10.1007/978-3-642-20804-1_1, Springer-Verlag Berlin.

Skarlatoudis, A.A., Papazachos, C.B., Margaris, B.N., Theodulidis N., Papaioannou, Ch., Kalogeras, I., Scordilis, E.M. and Karakostas, V., 2003. Empirical peak ground-motion predictive relations for shallow earthquakes in Greece, Bull. Seism. Soc. Am., 93, 2591-2603.

Skarlatoudis, A.A., Papazachos, C.B., Margaris, B.N., Theodulidis N., Papaioannou, Ch., Kalogeras, I., Scordilis, E.M. and Karakostas, V., 2007. Erratum to "Empirical peak groundmotion predictive relations for shallow earthquakes in Greece", Bull. Seism. Soc. Am., 97(6), 2219-2221, doi: 10.1785/0120070176.

Somerville, P.G., 1993. Engineering applications of strong ground-motion simulation, Tectonophysics, 218, 195-219.

Taymaz, T., Jackson, J. and McKenzie, D., 1991. Active tectonics of the north and central Aegean Sea, Geophys. J. Int., 106, 433-490.

Wald, D.J. and Allen, T.I., 2007. Topographic slope as a proxy for seismic site conditions and amplification, Bull. Seism. Soc. Am., 97(5), 1379-1395, doi: 10.1785/ 0120060267.

Wessel, P. and Smith, W.H.F., 1998. New improved version of the Generic Mapping Tools released, EOS Trans. AGU 79, 579.

Zwick, P., McCaffrey, R. and Abers, G., 1994. MT5 Program, IASPEI Software Library, 4. 